Check for updates

Cite this: Mater. Adv., 2021, 2, 5465

Received 8th March 2021, Accepted 7th July 2021

DOI: 10.1039/d1ma00206f

rsc.li/materials-advances

\title{
The development of poly(ethylene oxide) reinforced with a nanocellulose-based nanocomposite polymer electrolyte in dye-sensitized solar cells
}

\author{
Mohd Saiful Asmal Rani, (D) *a Nur Athirah Abdullah, ${ }^{\text {b }}$ Muhammad Hanif Sainorudin, ${ }^{b}$ \\ Masita Mohammad*b and Salmiah Ibrahim ${ }^{\mathrm{c}}$
}

\begin{abstract}
Here, we describe a nanocomposite polymer electrolyte prepared using a solution casting technique. Polyethylene oxide (PEO), lithium iodide (LI), and nanocellulose (NCC) extracted from palm oil empty fruit bunch (EFB) were used to prepare electrolyte films. The structural and electrical behaviors of the prepared films were studied using Fourier-transform infrared spectroscopy, X-ray diffraction, and electrochemical impedance spectroscopy. At room temperature, the device impregnated with 0.6 wt\% NCC showed the optimum ionic conductivity of $(1.03 \pm 0.5) \times 10^{-3} \mathrm{~S} \mathrm{~cm}^{-1}$. Complexation between the PEO polymer, lithium iodide, and NCC was confirmed from infrared spectroscopy data and the XRD patterns of the nanocomposite polymer electrolytes. A photovoltaic response efficiency of $2.12 \%$ was achieved using the highest-conducting film in a dye-sensitized solar cell (DSSC), and this showed the film to be suitable for DSSC applications.
\end{abstract}

\section{Introduction}

Solid polymer electrolytes (SPEs) are prepared by complexing polymers with metal salts. SPEs have received considerable attention due to their promising potential applications, not only in all-solid-state rechargeable batteries, but also in other electrochemical devices such as supercapacitors, batteries, electrochromic windows and sensors. ${ }^{1-5}$ SPEs have many advantages such as relatively high mechanical stability and good electrode-electrolyte contacts as well as the ease of fabricating devices made with them and their leakage-free character. $^{6-9}$ Despite their many advantages, SPEs still exhibit low conductivity at room temperature, and the working efficiency for their application in electrochemical devices is still not satisfactory. ${ }^{10-14}$

Hence, to improve the conductivity as well as the other properties of SPEs, modifying the polymer host for polymer electrolytes may be considered because the polymer host plays an important role for the ion transport mechanism in polymer electrolytes. ${ }^{15,16}$ Incorporating nanocellulose (NCC) into

\footnotetext{
${ }^{a}$ School of Materials and Mineral Resources Engineering, Engineering Campus, Universiti Sains Malaysia, Nibong Tebal 14300, Penang, Malaysia. E-mail: iker.asmal55@gmail.com

${ }^{b}$ Solar Energy Research Institute (SERI), Universiti Kebangsaan Malaysia, 43600 Bangi, Selangor, Malaysia. E-mail: masita@ukm.edu.my ${ }^{c}$ Centre for Foundation Studies in Science, University of Malaya, Kuala Lumpur 50603, Malaysia
}

polymer matrices as a means of increasing mechanical stability levels of the SPEs has become a popular research topic. In addition, impregnating NCC into SPEs also improves the anode-polymer interfacial stability as well as the electrochemical and transport properties of polymer electrolytes. ${ }^{17-19}$ The presence of NCC can also enhance the amorphicity of the sample, create favorable pathways for ionic conduction, and immobilize the anions. NCC displays many advantages: in addition to its low cost and high abundance and the ability to produce it from naturally occurring sources, it also exhibits good mechanical properties, low density, biodegradability and relatively good surface reactivity, and hence provides better properties for its role as a reinforcing phase in nanocomposites than do micro/macro cellulose composites. ${ }^{20,21}$

Dye-sensitized solar cells (DSSCs), have attracted considerable attention since the first report written about them by O' Regan and Grätzel in 1991 due to their simple preparation procedure, low cost, environmental compatibility and good performance under diffuse light conditions. $^{22}$ Bella and co-researchers developed a green, efficient and stable DSSC using inexpensive elements, achieving a quite impressive efficiency for a water-based solar cell. ${ }^{23}$ On the other hand, a novel polymer-based platform was used to fabricate an innovative self-powered device with two electrodes that integrates energy harvesting and storage sections. A procedure involving oxygeninhibited UV-light-promoted crosslinking has been used to produce a multifunctional polymeric layer composed of two 
poly(ethylene glycol)-based sections separated by a perfluorinated barrier, and a remarkable $3.72 \%$ efficiency was obtained. ${ }^{24}$ In DSSC applications, the SPEs must contain a redox ion couple (iodide/triiodide ions) to be used for regeneration of the oxidized dye. ${ }^{25,26}$ However, the function of the cation in the electrolyte system cannot be ignored because it also plays an important role for the process of converting light to electricity in the DSSC. ${ }^{27,28}$ The diffusion of electrons in the conduction band of $\mathrm{TiO}_{2}$ is considered to occur via an ambipolar diffusion mechanism. ${ }^{29-31}$ In these studies, the lithium cation $\left(\mathrm{Li}^{+}\right)$was used due to the above considerations and due to its small cationic radius allowing it to easily penetrate into the dye-coated $\mathrm{TiO}_{2}$ film and form ambipolar $\mathrm{Li}^{+}-\mathrm{e}^{-}$pairs with the electrons in the conduction band of $\mathrm{TiO}_{2}$. This feature has been indicated to increase the transport speed of electrons in the $\mathrm{TiO}_{2}$ network and enhance current density $\left(J_{\mathrm{SC}}\right)$ levels of the DSSCs. $^{32,33}$

In our current work, we set out to extract NCC from palm oil empty fruit bunch (OPEFB). Then, the derived NCC was incorporated with lithium iodide (LI) salt and the polymer host poly(ethylene oxide) (PEO) to produce nanocomposite polymer electrolytes (NPEs). The NPEs were investigated using FTIR spectroscopy, XRD and impedance analysis to study the structural and electrical properties of the corresponding film. The potential practicality of the polymer electrolyte in DSSCs was also investigated.

\section{Experimental}

\subsection{Materials}

The starting materials, namely samples of empty fruit bunch from palm oil, were collected from Sabah Softwood Sdn. Bhd., Tawau, Malaysia. Sodium hydroxide (99\%), sulphuric acid (98\%), sodium chlorite (80\%), isopropanol, and glacial acetic acid (99.5\%) were purchased from SYSTERM-chemAR (Malaysia). Poly(ethylene oxide) (PEO, $M_{\mathrm{w}}=600000 \mathrm{~g} \mathrm{~mol}^{-1}$, Sigma Aldrich), lithium iodide crystalline powder (99.9\% trace metals basis, LI, $M_{\mathrm{w}}=133.85 \mathrm{~g} \mathrm{~mol}^{-1}$, Sigma Aldrich), methanol $\left(M_{\mathrm{w}}=32.04 \mathrm{~g} \mathrm{~mol}^{-1}\right.$, Systerm), and iodine (Merck) were the chemicals used in this study. Ruthenium dye (N-719), platinum paste under the commercial name Platisol T, fluorine-doped tin oxide (FTO) with an impedance of $\sim 15 \Omega \mathrm{cm}^{-2}$ (Aubonne, Switzerland, Solaronix), and titanium dioxide $\left(\mathrm{TiO}_{2}\right)$ paste (DSL 18NR-AO) (New South Wales, Australia, DyeSol) were used for producing the DSSC components. All materials were used as received without further purification.

\subsection{Preparation of NCC and NPE}

2.2.1. Synthesis of NCC. OPEFB was cut into small pieces before being blended using a grinder machine to fibers with dimensions of approximately $0.03 \mathrm{~mm}$. The fibers were repeatedly washed with water and dried in a temperature-controlled oven at $60{ }^{\circ} \mathrm{C}$ for $18 \mathrm{~h}$. The sample was kept in an air-tight bag and placed in a desiccator until further analysis. A mass of $15 \mathrm{~g}$ of the sample was dewaxed with toluene-ethanol $(2: 1, \mathrm{v} / \mathrm{v})$ in a Soxhlet apparatus for $7 \mathrm{~h}$. The dewaxed fibers were sequentially delignified with acidified sodium chlorite (acetic acid was used to achieve a $\mathrm{pH}$ of 4 ) at $70{ }^{\circ} \mathrm{C}$ for $1 \mathrm{~h}$ and this process was repeated until the sample became white. Then, it was filtered to remove water-soluble components and washed until the $\mathrm{pH}$ was neutral. The resulting residue was then treated with sulphuric acid (64 wt\%) in a reaction flask. Samples of the solution from the hydrolysis process, each with a volume of $50 \mathrm{~mL}$, were added into six centrifuge tubes, respectively. Next, the centrifuge tubes were placed in a refrigerated benchtop centrifuge (Sartorius Sigma 3-18 K), which was then operated at a speed of $10000 \mathrm{pm}$ for 15 minutes at a temperature of $4{ }^{\circ} \mathrm{C}$. After 15 minutes, the samples were removed from the centrifuge. Next, a volume of $50 \mathrm{~mL}$ of distilled water was added into each centrifuge tube, and they were placed in the centrifuge. The process was repeated five times. After that, the collected solid residues were treated with a solution of $1 \% \mathrm{NaOH}$ until a neutral $\mathrm{pH}$ was achieved. The resulting material was subjected to freeze drying, and in this way the NCC was obtained.

2.2.2. Preparation of NPE films. To prepare the NPE films, $1 \mathrm{~g}$ of PEO was at a fixed weight percentage ratio combined with $20 \mathrm{wt} \% \mathrm{LI}$ (the optimized salt system from our work) incorporated with NCCs of different weight percentages (NCC A $=0.2$, NCC B $=0.6$ and NCC C $=1 \mathrm{wt} \%$ ). All materials were dissolved in $40 \mathrm{~mL}$ of $1 \%$ acetic acid and continuously stirred at $40{ }^{\circ} \mathrm{C}$ for $24 \mathrm{~h}$ until a homogenous solution was obtained. The mixture was then poured into a glass Petri dish and dried in a vacuum oven at $35{ }^{\circ} \mathrm{C}$ for $12 \mathrm{~h}$. The free-standing film formed was then slowly peeled off from the glass Petri dish and kept in a desiccator.

\subsection{Characterization techniques}

To study the interaction between PEO, LI and NCC, FTIR analysis was carried out using a PerkinElmer Frontier FTIR spectrophotometer in the range 4000 to $550 \mathrm{~cm}^{-1}$ with a scanning resolution of $2 \mathrm{~cm}^{-1}$. X-Ray diffraction (XRD) was performed to analyze the crystallinities of the samples. Impedance measurements were taken using a SOLARTRON 1260 impedance analyzer in order to study the ionic conductivities of the samples. The samples were sandwiched between stainless steel electrodes, and measurements were taken over the frequency range $10 \mathrm{~Hz}$ to $5 \mathrm{MHz}$ with a $100 \mathrm{mV}$ dc amplitude. The bulk resistance $\left(R_{\mathrm{b}}\right)$ value was obtained from the Nyquist plot. The ionic conductivity value was calculated using the equation

$$
\sigma=\frac{t}{R_{\mathrm{b}} A}
$$

where $t$ is the sample thickness and $A$ is the sample-electrode contact area.

\subsection{DSSC fabrication and current density-voltage measurements}

For DSSC fabrication, commercial $\mathrm{TiO}_{2}$ paste was spread on a photoanode glass by using the doctor-blade technique and a counter-electrode glass was platinized using the brush-painting technique. Both the photo-anode and counter electrode were annealed at $450{ }^{\circ} \mathrm{C}$ for 30 minutes in order to improve the 
interconnection among particles and activate the quasi-transparent platinum layer, respectively. The $\mathrm{TiO}_{2}$ photoanode was then immersed in the dye solution (N719, $0.3 \mathrm{mM}$ ) for $24 \mathrm{~h}$ at room temperature. The PEO + LI + NCC solution was combined with iodine $(10: 1)$ and allowed to stand for $24 \mathrm{~h}$, after which it was cast on the $\mathrm{TiO}_{2}$ photoanode. After a few minutes, the counter electrode was placed on top of the dried electrolyte- $\mathrm{TiO}_{2}$ photoanode before being characterized. A Wonatech Zive MP2 multichannel electrochemical analyzer with a xenon light source and under AM 1.5 illumination $\left(100 \mathrm{~mW} \mathrm{~cm}^{-2}\right)$ controlled using a radiometer was deployed to record the current density-voltage $(J-V)$ data of the $\mathrm{FTO} / \mathrm{TiO}_{2}$-dye/PEO-LI-NCC/ $\mathrm{I}_{2} / \mathrm{Pt}$ DSSC. The illumination cell area was set to $1 \mathrm{~cm}^{2}$. Photoelectric performance measures such as fill factor (FF) and light-to-electricity energy conversion efficiency $(\eta)$ were calculated using eqn (2) and (3), respectively.

$$
\begin{gathered}
\mathrm{FF}=\frac{V_{\max } \times J_{\max }}{V_{\mathrm{OC}} \times J_{\mathrm{SC}}} \\
\eta=\frac{V_{\mathrm{OC}} \times J_{\mathrm{SC}} \times \mathrm{FF} \times 100}{P_{\text {in }}}
\end{gathered}
$$

In these equations, $V_{\mathrm{OC}}$ is the open-circuit voltage $(\mathrm{V}), J_{\mathrm{SC}}$ is the short-circuit current density $\left(\mathrm{mA} \mathrm{cm}^{-2}\right)$, and $P_{\text {in }}$ is the incident light power density $\left(\mathrm{mW} \mathrm{cm}{ }^{-2}\right)$, while $V_{\max }(\mathrm{V})$ and $J_{\max }\left(\mathrm{mA} \mathrm{cm}^{-2}\right)$ are, respectively, the voltage and current density in the $J-V$ curves at the point of maximum power output.

\section{Results and discussions}

\subsection{X-Ray diffraction (XRD)}

In the XRD profile of each nanocomposite, there were intense well-defined crystalline peaks at $2 \theta$ values of about $19^{\circ}$ and $23^{\circ}$ as illustrated in Fig. 1. These diffraction peaks can be assigned to characteristic (120) and (112/004) reflections of PEO. ${ }^{34}$ Islam and co-researcher made a similar observation when studying

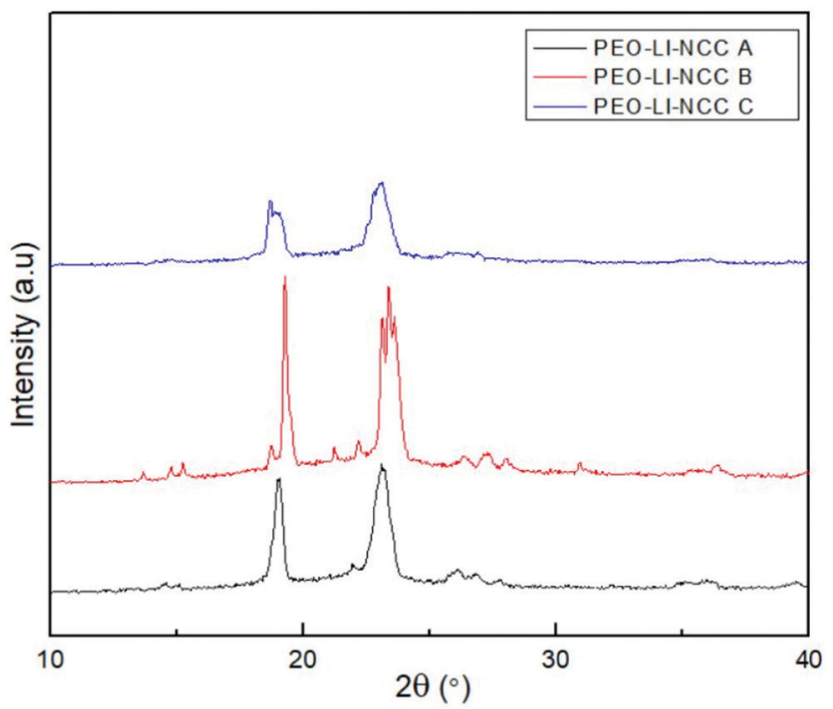

Fig. 1 XRD diffraction plots of PEO-LI-NCC A, PEO-LI-NCC B, and PEO-LI-NCC C. the influence of alkali treatment on the interfacial and physicomechanical properties of polylactic acid composites reinforced with industrial hemp fibers. The observation was attributed to the presence of a large content of lignin, which negatively influenced the nucleating ability of the raw fibers. In the case of bleached and hydrolyzed nanofiber-based composites, the removal of lignin and hemicellulose obviously promoted transcrystallization of the polymer chains. ${ }^{35}$

\subsection{FTIR analysis}

PEO displayed the characteristic FTIR bands at 2984, 1336, 1097,958 and $840 \mathrm{~cm}^{-1}$ related to $\mathrm{CH}$ stretching, $\mathrm{CH}_{2}$ wagging, $\mathrm{C}-\mathrm{O}-\mathrm{C}$ stretching, $\mathrm{CH}_{2}$ rocking and twisting and $\mathrm{C}-\mathrm{O}-\mathrm{C}$ bending, respectively, as illustrated in Fig. 2. The $\mathrm{OH}$ stretching absorption was negligible due to the high-molecular-weight PEO used in this study. Similar bands were observed in the spectra of all of the investigated composite samples. Because the content of the NCC was too small compared to that of the high-molecular-weight PEO, there were no clear absorption signals related to the NCC from various treatment stages.

\subsection{Electrochemical analysis}

Fig. 3 shows the ionic conductivity levels of NPEs each as a function of NCC concentration at room temperature $(303 \mathrm{~K})$. PEO-20 wt\% LI showed a low ionic conductivity $(\sigma)$ of $(1.85 \pm 0.8) \times 10^{-4} \mathrm{~S} \mathrm{~cm}^{-1}$ at ambient temperature $(303 \mathrm{~K})$. The effects of the NCC content on the ionic conductivity of PEO-LI at four different levels, namely 0, 0.2, 0.6 and $1.0 \mathrm{wt} \%$, were examined. The NCC content dependence of ionic conductivity in the NPEs at room temperature is shown in Fig. 5. The ionic conductivity of the NPE first increased with increasing NCC content - up to a peak conductivity of $(1.03 \pm 0.5) \times 10^{-3} \mathrm{~S} \mathrm{~cm}^{-1}$ for $0.6 \mathrm{wt} \% \mathrm{NCC}-$ and then started to decrease with further addition of NCC. The increase in conductivity can be explained by the NCC particles acting as

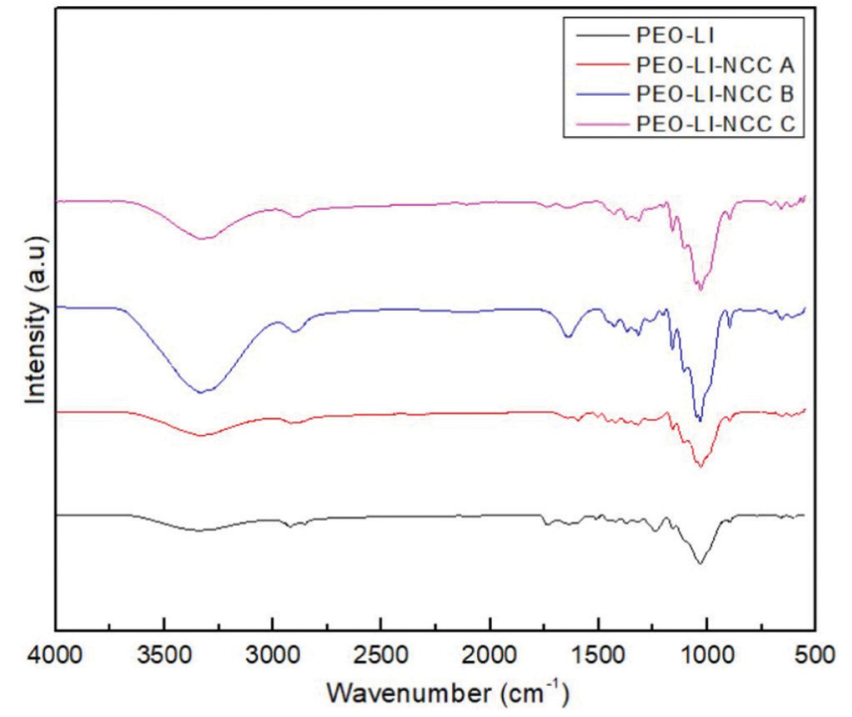

Fig. 2 FTIR spectra of PEO-LI, PEO-LI-NCC A, PEO-LI-NCC B, and PEO-LI-NCC C. 


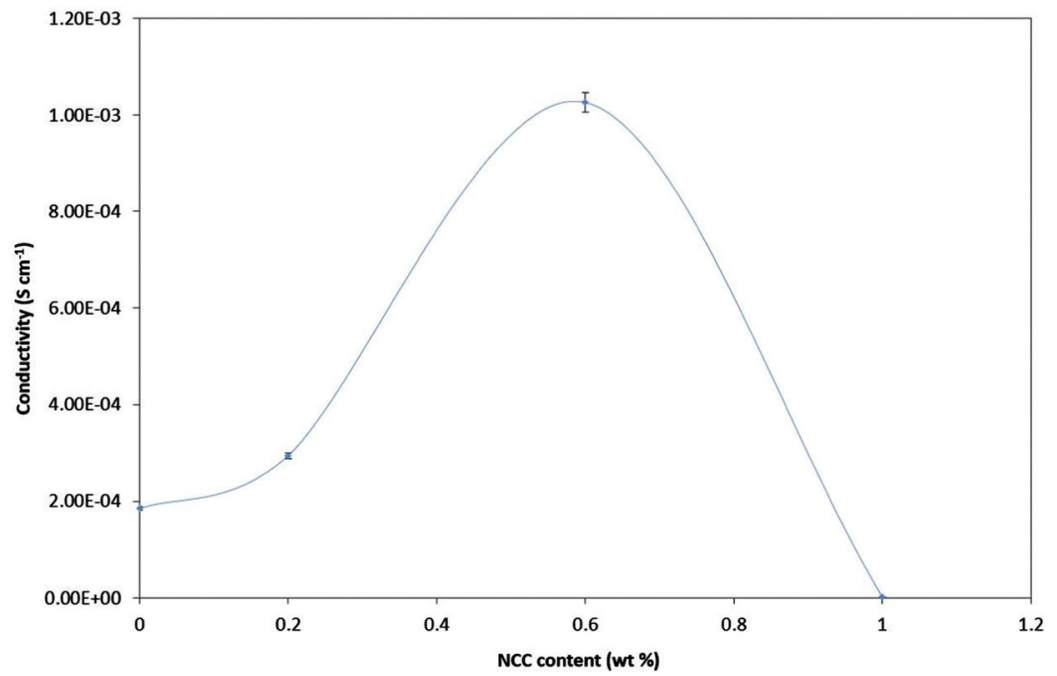

Fig. 3 Ionic conductivity of the PEO-LI-NCC system at room temperature.

nucleation centers for the formation of minute crystallites. ${ }^{36}$ In addition, the NCC particles presumably aided in the formation of the amorphous phase in the polymer electrolyte. ${ }^{37}$ The conductivity enhancement in this system may have been due to the formation of new kinetic paths at polymer-ceramic boundaries. ${ }^{38}$ In any case, the decreased $T_{\mathrm{g}}$ presumably resulted in increased segmental movements of the polymer chains as reflected by increased conductivity in the amorphous or relatively poorly ordered regions. ${ }^{39}$ However, as described above, the conductivity was found to decrease after an optimum concentration of NCC was crossed. As the optimum concentration was attained, and then on further addition of NCC, a continuous non-conductive phase was presumably built up by a large amount of nanofillers as an electrically inert component that would block ion transport, resulting in an increase in total resistance of the composite polymer electrolyte. ${ }^{40,41}$

A study of the temperature dependence of ionic conductivity was performed to investigate the influence of thermal treatment on the NPE. ${ }^{42}$ Temperature dependence of conductivity for each of several NPEs having different compositions of NCC was studied in the temperature range $303-348 \mathrm{~K}$. Such measurements can be used to analyze the mechanism of ionic conduction of NPEs. ${ }^{43,44}$ The dependence of ionic conductivity on temperature for each of the NPE films is presented in Fig. 4.

The linearity of the plots of $\log \sigma v s .1000 / T$ plots suggested an Arrhenius behaviour or thermally assisted behaviour of ionic conductivity, one that can be expressed as

$$
\sigma=\sigma_{0} \exp \left(-E_{\mathrm{a}} / k T\right)
$$

where $\sigma_{0}$ is the pre-exponential factor, $E_{\mathrm{a}}$ is the activation energy, $k_{\mathrm{b}}$ is the Boltzmann constant and $T$ is the absolute temperature. From Fig. 4, we found that the ionic conductivity of each NPE increased with increasing temperature. This relationship can be explained by a promotion of segmental motion of polymer chains by higher temperatures. The regression values, $R^{2}$, obtained from the linear fits of the Arrhenius plots were found to be close to unity $\left(R^{2} \sim 1\right)$; the plots did not show any abrupt

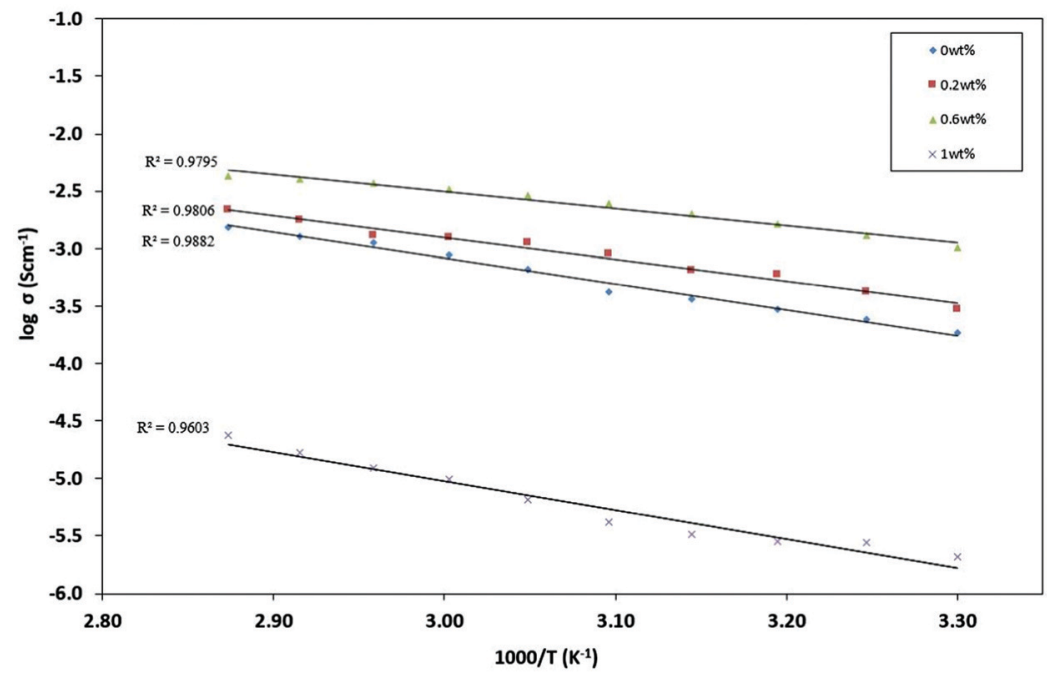

Fig. 4 The temperature dependence of the conductivity of the PEO-LI-NCC system. 


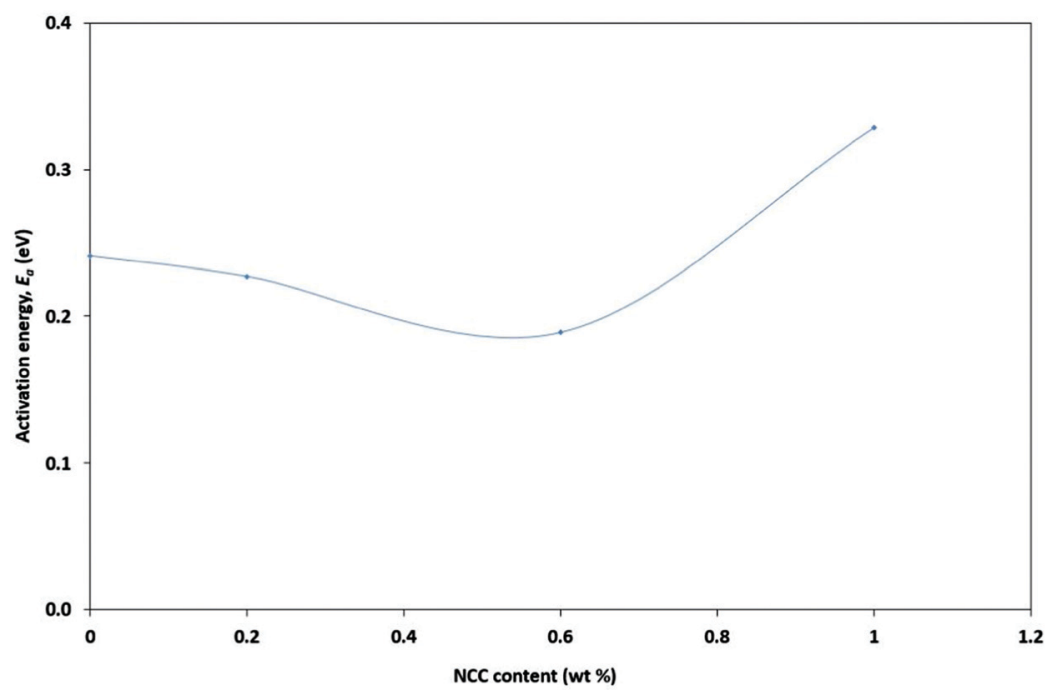

Fig. 5 Activation energy for the PEO-LI-NCC system.

jump with temperature, indicating that there was no phase transition in the polymer film structures within the selected temperature range. $E_{\mathrm{a}}$ was calculated from the plots in Fig. 4 and found to decrease with the increasing concentration of NCC (until $0.6 \mathrm{wt} \%$ ). This result showed that NCC facilitated ionic transport in the system, hence increasing the ionic conductivity.

\subsection{DSSC performance}

In order to assess the performance of the NPE, the sample was fabricated in an FTO/TiO ${ }_{2}$-dye/PEO-LI- 0.6 wt $\%$ NCC $/ \mathrm{I}_{2} / \mathrm{Pt}$ DSSC and tested under illumination of light. A photocurrent densityvoltage $(J-V)$ curve of the DSSC is shown in Fig. 6 . The photovoltaic parameters $J_{\mathrm{SC}}, V_{\mathrm{OC}}, \mathrm{FF}$ and $\eta$ were obtained from the

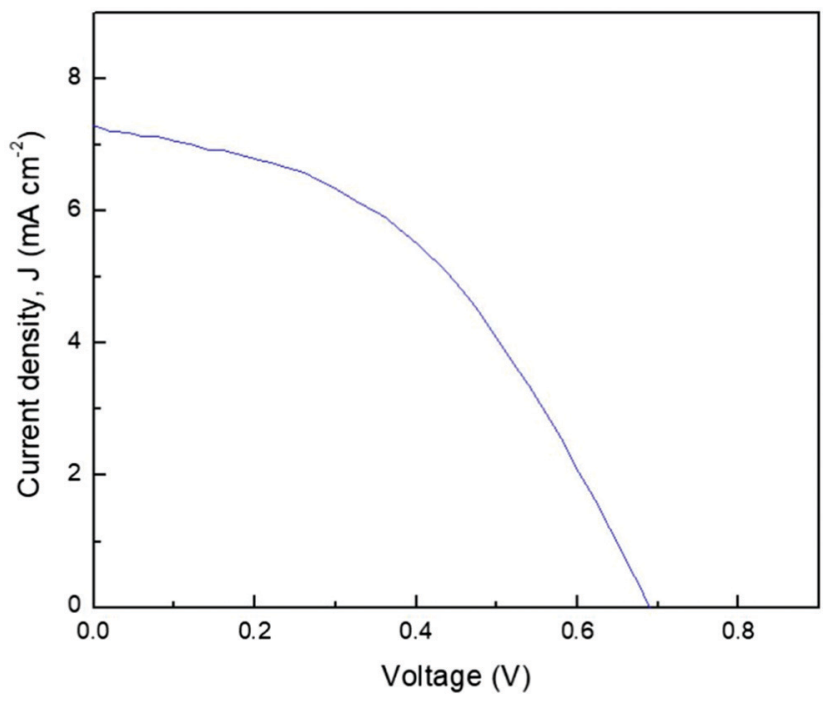

Fig. 6 Photocurrent density versus cell potential $(J-V)$ for a DSSC fabricated using PEO-LI-0.6 wt\% NCC. intersection of current and voltage from the $J-V$ curve for the device under illumination. ${ }^{45}$ The DSSC showed a photovoltaic response with a $J_{\mathrm{SC}}$ of $7.3 \mathrm{~mA} \mathrm{~cm}{ }^{-2}, V_{\mathrm{OC}}$ of $0.7 \mathrm{~V}, \mathrm{FF}$ of 0.44 and $\eta$ of $2.21 \%$. This efficiency value was higher than the $0.29 \%$ and $0.76 \%$ values reported by Singh et al. for, respectively, PVA: $\mathrm{NH}_{4} \mathrm{I} / \mathrm{I}_{2}$ and PVPI:IL- $\mathrm{I}_{2}$ polymer electrolytes in solid forms. ${ }^{46}$ This result showed that even though $\mathrm{I}^{-}$ions are important for regeneration of oxidized dye in a DSSC system, $t_{\mathrm{Li}^{+}}$cannot be too low because cations can help the ion easily penetrate into the dye-coated $\mathrm{TiO}_{2}$ film and hence increase the transport speed of electrons in the $\mathrm{TiO}_{2}$ network of the DSSC. ${ }^{47}$ Thus, $0.6 \mathrm{wt} \%$ NCC was concluded to provide promising paths for electrolytes in a DSSC.

\section{Conclusions}

Free PEO-LI standing films with various NCC weight ratios were successfully prepared via performing a solution casting technique. Fourier-transform infrared spectroscopy analysis revealed evidence of NCC, lithium, and iodide ion interactions with the host polymer. According to impedance analysis, the ionic conductivity with $0.6 \mathrm{wt} \%$ NCC showed the greatest value, $(1.03 \pm 0.5) \times 10^{-3} \mathrm{~S} \mathrm{~cm}^{-1}$, which may be related to increased polymer backbone segmental motion. The lowest activation energy was also found for $0.6 \mathrm{wt} \%$ NCC. These factors may have contributed to the low energy required to provide conductive conditions and to the low relaxation period, which may be ascribed to an increase in ion mobility in the polymer matrix. The highest efficiency, $2.12 \%$, was achieved by using the DSSC containing $0.6 \mathrm{wt} \%$ NCC. As a result, the $0.6 \mathrm{wt} \%$ NCC NPE film was concluded to be suitable for DSSCs.

\section{Conflicts of interest}

There are no conflicts to declare. 


\section{Acknowledgements}

The authors would like to express their gratitude to the Malaysian Ministry of Education for financial support under the Fundamental Research Grant Scheme (FRGS/1/2019/TK10/ UKM/02/1) and the Centre of Research and Instrument Management, Universiti Kebangsaan Malaysia (MI-2019-018).

\section{References}

1 B. Scrosati, R. Neat, B. Scrosati and F. M. Gray, Polymer Electrolytes, 1997.

2 F. M. Gray, Solid polymer electrolytes, VCH New Tork, 1991.

3 L. S. Ng and A. A. Mohamad, J. Membr. Sci., 2008, 325, 653-657.

4 S. Rudhziah, M. S. A. Rani, A. Ahmad, N. S. Mohamed and H. Kaddami, Ind. Crops Prod., 2015, 72, 133-141.

5 M. P. Cipolla, G. L. De Gregorio, R. Grisorio, R. Giannuzzi, G. Gigli, G. P. Suranna and M. Manca, J. Power Sources, 2017, 356, 191-199.

6 A. Balducci, S. S. Jeong, G. T. Kim, S. Passerini, M. Winter, M. Schmuck, G. B. Appetecchi, R. Marcilla, D. Mecerreyes, V. Barsukov, V. Khomenko, I. Cantero, I. De Meatza, M. Holzapfel and N. Tran, J. Power Sources, 2011, 196, 9719-9730.

7 A. L. Agapov and A. P. Sokolov, Macromolecules, 2011, 44, 4410-4414.

8 M. S. A. Rani, N. S. Mohamed and M. I. N. Isa, Int. J. Polym. Anal. Charact., 2015, 20, 491-503.

9 M. S. A. Rani, M. H. Sainorudin, N. Asim and M. Mohammad, Int. J. Electrochem. Sci., 2020, 15, 11833-11844.

10 D.-W. Kang, D.-W. Kim, S. I. Jo and H.-J. Sohn, J. Power Sources, 2002, 112, 1-7.

11 S. Rajendran, M. R. Prabhu and M. U. Rani, Int. J. Electrochem. Sci., 2008, 3, 282-290.

12 M. S. A. Rani, N. H. Hassan, A. Ahmad, H. Kaddami and N. S. Mohamed, Ionics, 2016, 1-10.

13 R. Shanti, F. Bella, Y. Salim, S. Chee, S. Ramesh and K. Ramesh, Mater. Des., 2016, 108, 560-569.

14 M. S. A. Rani, N. S. Isa, M. H. Sainorudin, N. A. Abdullah, M. Mohammad, N. Asim, H. Razali and M. A. Ibrahim, Int. J. Electrochem. Sci., 2021, 16, 210354.

15 P. Jayathilaka, M. Dissanayake, I. Albinsson and B.-E. Mellander, Solid State Ionics, 2003, 156, 179-195.

16 M. S. A. Rani, S. Rudhziah, A. Ahmad and N. S. Mohamed, Polymers, 2014, 6, 2371-2385.

17 M. Forsyth, D. MacFarlane, A. Best, J. Adebahr, P. Jacobsson and A. Hill, Solid State Ionics, 2002, 147, 203-211.

18 S. Chung, Y. Wang, L. Persi, F. Croce, S. Greenbaum, B. Scrosati and E. Plichta, J. Power Sources, 2001, 97, 644-648.

19 A. M. Stephan and K. Nahm, Polymer, 2006, 47, 5952-5964.

20 N. A. Abdullah, M. S. A. Rani, M. Mohammad, M. H. Sainorudin, N. Asim, Z. Yaakob, H. Razali and Z. Emdadi, Polimery, 2021, 66, 157-168.

21 N. A. Abdullah, M. H. Sainorudin, M. S. A. Rani, M. Mohammad, N. H. Abd Kadir and N. Asim, Polimery, 2021, 66, 187-192.
22 B. O'regan and M. Grfitzeli, Nature, 1991, 353, 737-740.

23 F. Bella, L. Porcarelli, D. Mantione, C. Gerbaldi, C. Barolo, M. Grätzel and D. Mecerreyes, Chem. Sci., 2020, 11, 1485-1493.

24 A. Scalia, F. Bella, A. Lamberti, C. Gerbaldi and E. Tresso, Energy, 2019, 166, 789-795.

25 F. Bella, D. Pugliese, L. Zolin and C. Gerbaldi, Electrochim. Acta, 2017, 237, 87-93.

26 F. Bella, S. Galliano, M. Falco, G. Viscardi, C. Barolo, M. Grätzel and C. Gerbaldi, Green Chem., 2017, 19, 1043-1051.

27 B. Bhattacharya, J. Y. Lee, J. Geng, H.-T. Jung and J.-K. Park, Langmuir, 2009, 25, 3276-3281.

28 M. Gratzel, Nature, 2001, 414, 338-345.

29 J. Wu, Z. Lan, S. Hao, P. Li, J. Lin, M. Huang, L. Fang and Y. Huang, Pure Appl. Chem., 2008, 80, 2241-2258.

30 N. Kopidakis, E. Schiff, N.-G. Park, J. Van de Lagemaat and A. Frank, J. Phys. Chem. B, 2000, 104, 3930-3936.

31 N. Kopidakis, K. D. Benkstein, J. van de Lagemaat, A. J. Frank, Q. Yuan and E. A. Schiff, Phys. Rev. B: Condens. Matter Mater. Phys., 2006, 73, 045326.

32 F. Bella, D. Pugliese, J. R. Nair, A. Sacco, S. Bianco, C. Gerbaldi, C. Barolo and R. Bongiovanni, Phys. Chem. Chem. Phys., 2013, 15, 3706-3711.

33 F. Bella, S. Galliano, C. Gerbaldi and G. Viscardi, Energies, 2016, 9, 384.

34 C. Zhou, R. Chu, R. Wu and Q. Wu, Biomacromolecules, 2011, 12, 2617-2625.

35 M. S. Islam, K. L. Pickering and N. J. Foreman, Composites, Part A, 2010, 41, 596-603.

36 A. Chandra, P. C. Srivastava and S. Chandra, J. Mater. Sci., 1995, 30, 3633-3638.

37 N. Munichandraiah, L. G. Scanlon, R. A. Marsh, B. Kumar and A. K. Sircar, J. Appl. Electrochem., 1995, 25, 857-863.

38 J. Przyluski, M. Siekierski and W. Wieczorek, Electrochim. Acta, 1995, 40, 2101-2108.

39 Y. Horowitz, M. Lifshitz, A. Greenbaum, Y. Feldman, S. Greenbaum, A. P. Sokolov and D. Golodnitsky, J. Electrochem. Soc., 2020, 167, 160514.

40 J. P. Sharma and S. Sekhon, Indian J. Eng. Mater. Sci., 2005, 12, 557.

41 R. Kumar and S. S. Sekhon, J. Appl. Electrochem., 2009, 39, 439-445.

42 M. S. A. Rani, N. S. Mohamed and M. I. N. Isa, Mater. Sci. Forum, 2016, 846, 539-544.

43 S. Sharma, N. Dhiman, D. Pathak and R. Kumar, Ionics, 2016, 22, 1865-1872.

44 M. S. A. Rani, M. Mohammad, M. S. Sua'it, A. Ahmad and N. S. Mohamed, Polym. Bull., 2020, 1-23, DOI: 10.1007/ s00289-020-03382-2.

45 M. Y. A. Rahman, M. M. Salleh, I. A. Talib and M. Yahaya, Ionics, 2007, 13, 241-244.

46 B. Bhattacharya, S. K. Tomar, S. P. Pandey, H. W. Rhee and P. K. Singh, Int. J. Nanotechnol., 2012, 9, 1030-1039.

47 N. A. Dzulkurnain, M. S. A. Rani, A. Ahmad and N. S. Mohamed, Ionics, 2018, 24, 269-276. 